\title{
Introducing the Social Presence Model to Explore Online and Blended Learning Experiences
}

\author{
Aimee L. Whiteside \\ University of Tampa
}

\begin{abstract}
This study explores the level of social presence or connectedness, in two iterations of a 13month, graduate-level certificate program designed to help K-12 school leaders integrate technology in their districts. Vygotsky's Social Development Theory serves as the theoretical lens for this programmatic research. The methods include a case study approach for coding discussions for 16 online courses using the pre-established Social Presence coding scheme as well as conducting instructor and student interviews and collecting observation notes on over a dozen face-to-face courses. The results of this study suggest the need for further research and development on the Social Presence coding scheme. Additionally, this study unveiled the Social Presence Model, a working model that suggests social presence consists of the following five integrated elements: Affective Association, Community Cohesion, Instructor Involvement, Interaction Intensity, and Knowledge and Experience. Finally, this study also highlighted the importance of multiple data sources for researchers, the need for researchers to request access to participant data outside the formal learning environment, and the inherently unique challenges instructors face with multimodal literacy and social presence in blended learning programs.
\end{abstract}

\section{Introduction}

As social learning theorist Etienne Wenger (1998) proclaims, "We are social beings...this fact is a central aspect of learning” (p. 4-5). We crave connections among one another within our learning environments. As instructors, we feel that spark of connected energy when students discover they have the same hometown or when they share a love of a particular animal, similar hobbies or career interests. Though seemingly and deceptively small, these social connections can change students' perceptions and motivation for a course and influence the entire experience for everyone involved.

As a result, before we dive into the academic content, it is essential to allow time for students to connect and engage with others to develop relationships. In their landmark works on engagement, Conrad 
Introducing the Social Presence Model to Explore Online and Blended Learning Experiences

and Donaldson (2004; 2011) refer to this phase as "Social Negotiating” in their early work and "Connect" in their most recent work. These authors suggest that engagement serves as an essential part of an online experience and that it involves a careful, phased process. The basic component of these engaged, connective experiences involves a concept called social presence (Short, Williams, \& Christie, 1976; Whiteside, 2007).

This study addresses a gap in the literature by exploring social presence within a 13-month certificate graduate-level program designed with both online and face-to-face components. It examines the first two cohorts of a school technology leadership program. Thus, this research offers an in-depth, multi-year examination of coded online discussions, observation notes of face-to-face courses, and interview transcriptions in an effort to better understand the significance of social presence in a blended learning program.

\section{Literature Review}

Although many new online teachers equate social presence with learning, social presence actually drew its roots from computer-mediated communication (CMC) rather than from the learning sciences (Lowenthal, 2010). It grew out of the telecommunication era of the late 1960s and 1970s when organizations began investing more time, money, and infrastructure into teleconferencing. At this time, CMC researchers viewed social presence as that which was lost or missing from the communicative experience (Short, Williams, \& Christie, 1976). These early researchers refer to social presence as the "degree of salience of the other person in a mediated communication and the consequent salience of their interpersonal interactions” (Short, Williams, and Christie, 1976, p. 65).

Then, as various interactive and other communication media evolved, such as interactive television, video streaming, and online learning environments, both Tammelin (1998) and (Whiteside, 2007) suggests a flurry of definitions for social presence emerged. Despite the myriad of definitions, Ruth Rettie, Professor at Kingston University, suggests social presence still remains nebulous. Rettie (2003) categorizes early social presence research into two very distinct categories: a) research that addresses social presence as a "property of a medium in mediated communication"; and b) research that "refers to the perceptions, behaviors, or attitudes of the participants in a mediated interaction." The first of Rettie's categories sees social presence as simply a lost or missing attribute of the communication within the medium. In Rettie's second category of social presence research, social presence grows beyond "that which was lost” in the process, yet social presence exists as a byproduct of the participants' perceptions, behaviors, and attitudes within the medium (Gunawardena, 1995; Gunawardena, Lowe \& Anderson, 1997; Gunawardena \& Zittle, 1997; McIssac, \& Gunawardena, 1996).

As the focus shifted away from interactive television and toward online and blended learning experiences, the research in social presence began to advance beyond Rettie's two original categories and into a third "era" (Oztok, \& Brett, 2011). Curiously, though, this shift did not make social presence any easier to understand and new definitions continued to emerge from case study research. For example, Polhemus, Shih \& Swan (2001) and Tu (2002) explored a one-semester online course in respective studies. These authors suggest that presence is a complex, multifaceted concept that requires further research to understand what comprises social presence and how it affects teaching and learning. Additionally, Na Ubon and Kimble (2003) studied multiple years of an online graduate certificate program. The overall findings for all of the above studies suggest: (a) higher levels of affect, cohesion, and interaction equate to higher levels of social presence; and (b) more research is needed in regard to social presence (Na Ubon and Kimble, 2003; Polhemus, Shih \& Swan, 2001; Swan \& Shih, 2005; Tu, 2002).

About the same time, University of Calgary Professor D. Randy Garrison and his colleagues continued crafting the Community of Inquiry (COI) Model. The COI Model extends Rettie's categories by moving away from mere behaviors and focusing on the creation of "deep and meaningful (collaborateconstructive) learning experiences” (Garrison, “Community of Inquiry Model”; Garrison, 2009; Garrison, 
Introducing the Social Presence Model to Explore Online and Blended Learning Experiences

2011). Garrison, Anderson, and Archer (2000; 2010) explain the COI as the interconnection of three equal presences: social presence, teacher presence and cognitive presence in relationship to the educational experience. Rourke, Garrison, Anderson and Archer (1999) unveiled a coding scheme which was extended by scholar Karen Swan and her colleagues (2001; 2002). With the emergence of the COI and the Social Presence Coding Scheme, much of the contemporary research in social presence began to gravitate toward this model (Garrison, Anderson, \& Archer, 2010; Garrison \& Arbaugh, 2007). Since its inception in 1996, contemporary researchers employed the COI Model in dozens of studies across various content areas (Arbaugh, 2005; Garrison \& Akyol, 2012; Lomicka \& Lord, 2007; Lowenthal \& Dunlap, 2010), different learning technologies (Daspit \& D'Souza, 2012; Dunlap \& Lowenthal, 2009; Nippard \& Murphy, 2007; Shea \& Bidjerano, 2010), and various types of presence (Boston et al; Cleveland-Innes \& Campbell, 2012; Cleveland-Innes, Ally, Wark, \& Fung, 2013; Dunlap, \& Lowenthal, 2014; Garrison, \& Cleveland-Innes 2005; Nagel \& Kotze, 2010; Richardson \& Swan, 2003; Shea \& Bidjerano, 2009a; Shea \& Bidjerano, 2009b; Shea, Li \& Pickett, 2006; Swan \& Shih, 2005; Wise, Chang, Duffy \& del Valle, 2004).

In recent years, researchers have made many discoveries about social presence in relation to learning environments, emerging technologies, innovative pedagogies and instructional strategies. Yet, we still struggle to understand the potential of social presence in programs, especially blended learning programs. This study seeks to explore two iterations of one specific blended learning program through a sociocultural lens to gain a better understanding of social presence.

\section{Method}

This study explored the level of social presence in a graduate-level certificate program at a large Midwestern university designed to help K-12 school leaders integrate technology in their districts (Hughes, McLeod, Brahier, Garrett Dikkers \& Whiteside, 2005; McLeod “CASTLE in Education”). The program consisted of fifteen one-credit courses taught over thirteen months, and this study explored two separate iterations, or cohorts, of this program as well as interview transcriptions and observation notes in a four-year data collection process.

The participants in this program included superintendents, principals, technology coordinators, media specialists, teachers and other school leaders. The first, Cohort 1, consisted of seventeen participants, and the second, Cohort 2, consisted of five participants. There was a mix of ages, genders and races in each cohort. Each cohort began their first face-to-face session in July with four, one-credit courses during an intensive six-day session. The cohort then transitioned to two fifteen-week terms of online coursework and finally, returned to campus for a four-day, face-to-face facilitation of their final three credits. Some examples of courses were as follows: School Technology Funding, Staff Technology Development and Support, School Technology Policy Issues, School Management and Technology, DataDriven Decision-Making I, Legal and Ethical Issues in School Technology, and School Technology Safety and Security.

This study featured the author in the role of participant-observer, as a curriculum coordinator in the program. It explored the first two cohorts of this program, which equated to 26 months of data from nearly thirty courses. The data collection process for this study began in Summer 2003 and ended in Spring 2007. Despite the age of this data, the study presents one of the few multi-year studies on social presence at the program level. Therefore, these findings are both relevant and significant today because social presence is growing in importance and because of the dearth of multi-year programmatic research for programs blended of online and face-to-face instructional components.

The research questions explored were as follows: (a) How can coded online discussions, face-toface observation notes, and interview transcriptions illustrate social presence in a learning community?; and (b) How does social presence affect blended learning programs and vice versa? The methods included coding the online discussions for sixteen online courses using a pre-established Social Presence Coding 
Scheme as well as examining instructor and student interview transcriptions and the author's observation notes from over a dozen face-to-face courses.

\section{Theoretical Lens: Vygotsky's Social Development Theory}

As a guiding framework, this study employed the lens of Lev Vygotsky’s Social Development Theory. This framework offers a very different approach to social presence than the commonly-used Social Presence Theory (Short, Williams and Christie, 1976). Whereas, the Social Presence Theory views social presence sensing the "real person" during the online communicative experience, Vygotsky's (1986; 1978) sociocultural approach examines social presence holistically within a given contextual situation. Specifically, this study centered on two guiding concepts within Vygotsky's Social Development Theory from Mind in Society (1976) and Thought and Language (1986): inner speech and zone of proximal development (ZPD). Inner speech helps us understand how thoughts move to written language in online discussions, and ZPD involves the distance between what a student can learn independently and what he/she can learn with competent assistance.

Vygotsky's notion of inner speech illustrates how learners need collaboration in the process of moving from mere thoughts to actual speech. Initially, according to Vygotsky, the learner develops speech-for-oneself as he or she reflects upon their initial thoughts. Then, the learner shares these thoughts with others in a process called speech-for-others in an effort to achieve validation through the learner's peers. As Vygotsky (1986) states, "It is a complex, dynamic process involving the transformation of the predicative, idiomatic structure of inner speech into syntactically articulated speech intelligible to others" (p. 249). Vygotsky suggests that students learn from reflecting on their own thoughts and then sharing those thoughts with their peers and instructors. Although Vygotsky's work was conducted long before the advent of online learning, this author contends that his concept of inner speech sheds light into understanding how language and interaction with others online enhances the learning process in blended and online learning experiences. The concept of inner speech helps us understand the ways in which students reflect on the material, interact with others, and articulate their learning in online discussions. For example, inner speech unfolds online when students initially lurk quietly and reflect on the material. Then, they read others' posts, and add their own contribution. Next, this post prompts the instructor(s) and students to add to each other's posts. Finally, inner speech experiences allow participants in online discussions to unpack, articulate, and understand the material. Thus, other students and instructor(s) often spark different connections for each other that promote further individual articulation and understanding of the material. Additionally, inner speech is often illustrated in this study when an instructor helps a student to enrich and expand their reflections; examples of this concept will be presented in the findings of this study.

Whereas inner speech helps students to better articulate their understanding of individual concepts, the zone of proximal development (ZPD) exemplifies the overall amount of "present knowledge" obtained during a learning experience. Vygotsky (1978) defines the zone of proximal development as "the distance between the actual developmental level as determined by independent problem solving and the level of potential development as determined through problem solving under adult guidance or in collaboration with more capable peers” (p. 86). Vygotsky suggests there are three different zones: present knowledge, proximal zone, and distal zone. The ZPD, or zo-ped as Vygotsky often called it, relates to expanding one's present knowledge into the proximal zone. Furthermore, as one of Vygotsky's contemporary theorists, Wells (2000), contends there is a relationship between knowledge acquisition and the social aspects of learning. He states, "For learning to occur in ZPD, [there must be]...a willingness on the part of all participants to learn with and from each other" (Wells, 2000, p. 324). Likewise, Salomon and Perkins (1998) suggest the social aspects of learning within ZPD results in an increased level of cognitive performance. These authors reflect on how learning is contextual and "highly dependent on particular cultural and social situations” (Salomon \& Perkins, 1998, p. 7). In sum, the ZPD serves as a powerful model that illustrates how learning increases through collaborative experiences with both instructors and peers. 


\section{Case Study Approach and Coding Scheme}

Within the methodological lens, this study employs discourse analysis within a case study approach (Merriam, 1998; Stake, 1998; Stake, 2000; Yin, 2003). Following the expert advice of Twigg (2001) and her colleagues, this research explores a rich source of data to illuminate the unique paradigmatic and pedagogical shifts involved in education. In short, the intent of this study is not to generalize to different educational environments. Instead, it intends to explore research questions within a specific case study and then suggest areas that may need additional exploration.

This study examines face-to-face observation notes from over a dozen courses, interview transcriptions (for two instructors and four students), and students' online discussion messages for sixteen courses using the pre-established Social Presence Coding Scheme developed by Rourke, Anderson, Garrison and Archer (1999), Polhemus, Shih \& Swan (2001), and Swan (2002). Table 1 illustrates how the Social Presence Coding Scheme divides social presence into three categories and offers fourteen codes to help capture instances of social presence.

Table: Social Presence Coding Scheme

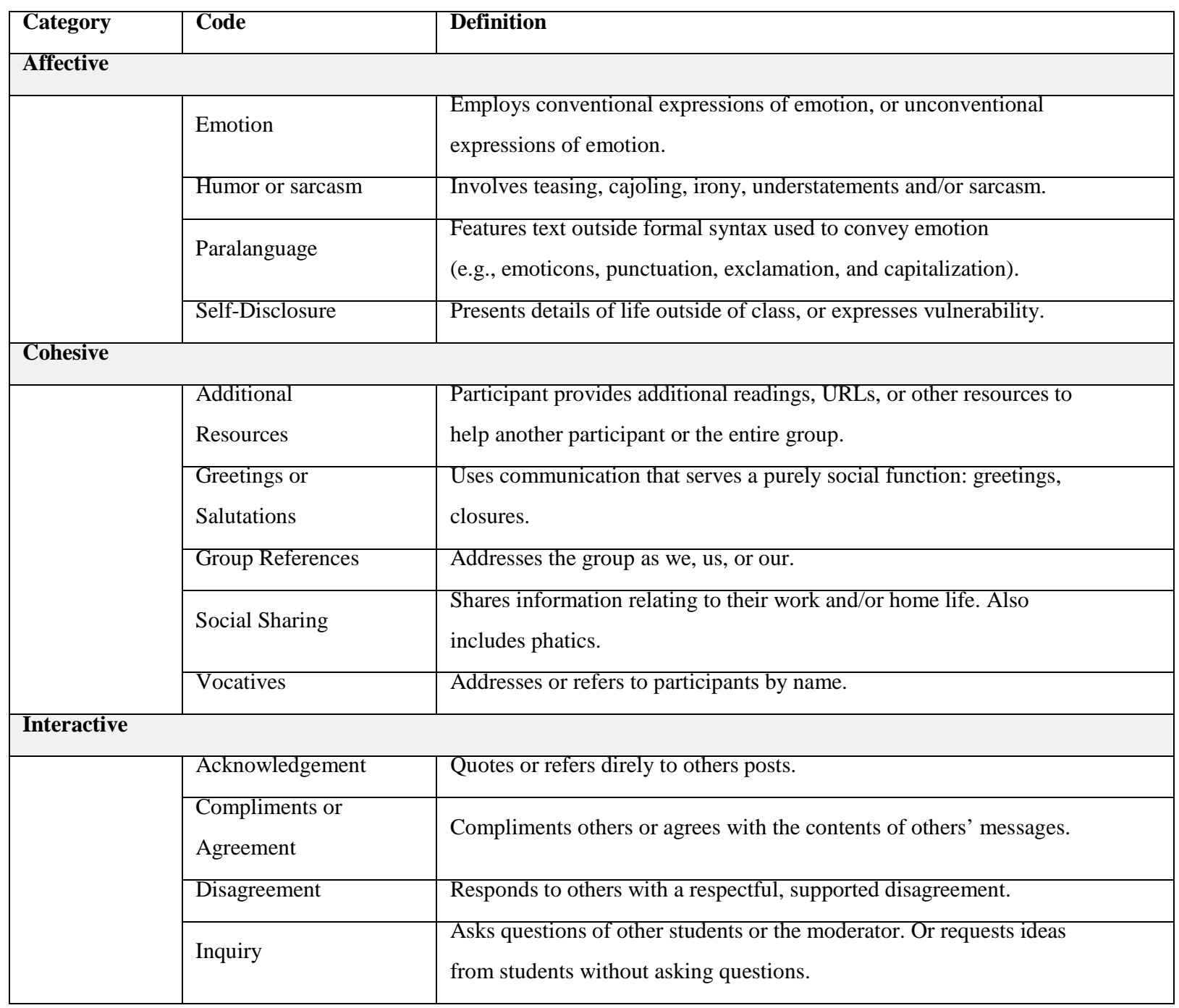

Additionally, this study draws upon the discursive psychology form of discourse analysis, which is based on Vygotskian principles. Phillips and Jorgensen (2002) explain that this form of discourse analysis explores "psychological processes" beyond "individual information processing" and understands them as "social activities" (p. 5). These authors explain that discursive psychology draws from "the works of 
Bakhtin, Mead and Vygotsky" and view "minds and selves as constructed through the internalization of social dialogues" that are "situated language use in the contexts in which it takes place" (p. 108). Since the study involves a discourse community of school technology leaders situated within a specific cohortbased program, discursive psychology matches well with the program and the theoretical framework.

Figure 1 provides an example of a discussion post from Cohort 1 coded using NVivo, a qualitative data analysis tool. The codes appear in the bars on the right-hand side of the screen. It is noteworthy that the unit of analysis is at the sentence level and that all participants have pseudonyms in this example and throughout this manuscript.
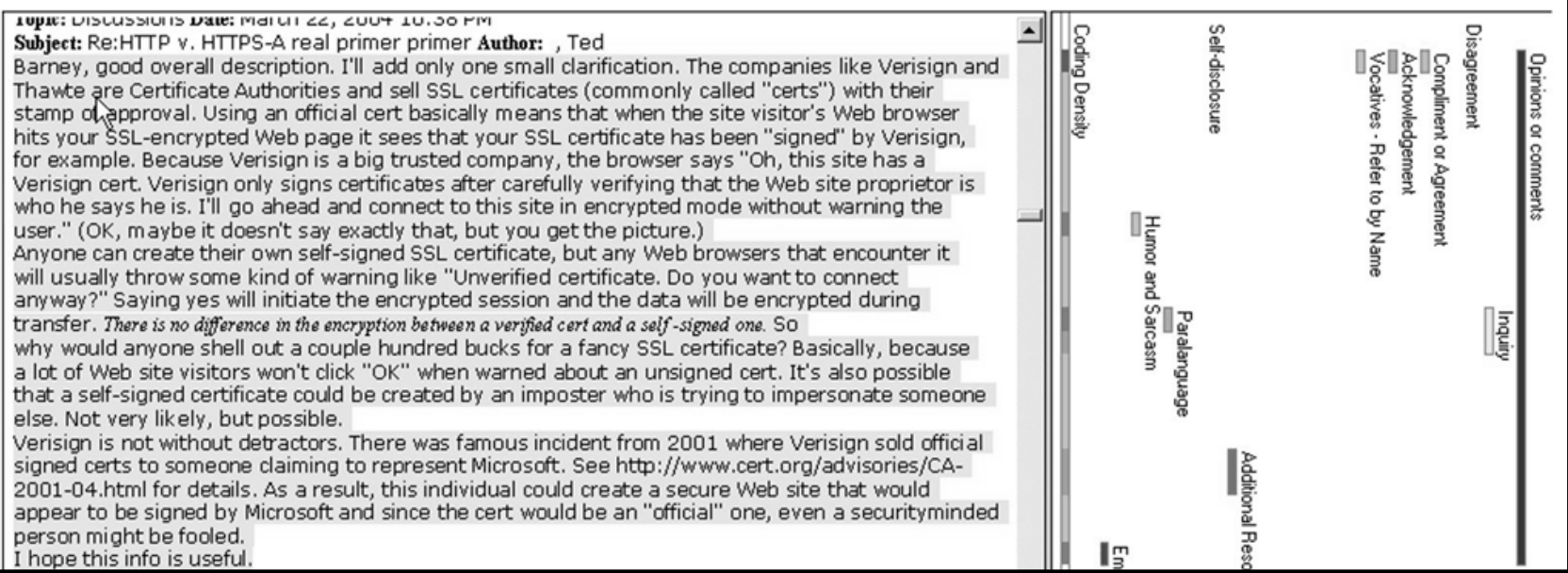

Figure 1: An example discussion post coded in NVivo

This example provides a snapshot of the coding applied to the discussions in sixteen online courses of this program. For example, Ted agrees with his classmate Barney, and refers to him by name. As a result, this section is coded with four different codes: Compliment or Agreement, Acknowledgement, Vocative (Refer to by Name), and Opinion or Comment. He brings in his expertise with a bit of humor as well as with a question, which is coded as both Humor and Sarcasm and as Inquiry (see Figure 1). He uses italics in this passage, which is coded for Paralanguage. Ted provides resources to help Barney and his classmates, which are coded as Additional Resources. Finally, he indicates that he "hopes" the information he provides serves them well, which is coded for Emotion.

Additional data artifacts for this study include the author's observation notes from over a dozen face-to-face courses as well as two instructor and four student interview transcriptions. The next section reports on the results of the coded data, observation notes and interview transcriptions.

\section{Results}

The data analysis process for this study yielded a number of findings. The results noted that instructors and students in this study both greatly value social presence. Also, the data analysis process resulted in contradictory results among the data artifacts, which ultimately revealed some shortcomings in the Social Presence Coding Scheme. These findings led to the formation of the Social Presence Model.

\section{Value and Importance of Social Presence}

The resulting data suggests that in this program social presence carries great value and importance for instructors and students alike. Interestingly, while students see their role in cultivating social presence all the way through the program, the data suggests that instructors may feel they bear more responsibility in the early stages of the program. One of the instructors, Dr. Mike Stanley, mentioned that learners have "one key responsibility" and that is to "take on a very natural responsibility of connecting with each other" (personal communication, May 3, 2006). Stanley commented that, after he fulfills his role of creating ice breakers and "opportunities for them to connect with each other," the students need to step up 
and be present.

Lydia, a student in Cohort 1, commented that social presence extends past course content and into truly understanding a cohort member. She stated: "Social presence [is]...being able to get past the book knowledge and [about] understanding each other and understanding the relationship the human aspect of the person" (Lydia, personal communication, July 22, 2005). She found that "social presence" means having a "relationship with your colleagues and apply[ing] your knowledge..." When asked to rate the importance of social presence on a one to five scale where five represents the highest level of importance, Lydia said, "For me, it would be a five." Another student in Cohort 1, Jerry, commented that social presence for him was "the level of comfort and trust you feel with a person in interacting with them" (personal communication, September 7, 2005). Jerry suggested that there were a number of benefits of social presence in the online component of the blended learning program, including not "fighting for the same attention" in person. He explained that the "stigma is always that, well, online is so impersonal...Well, the truth is in a lot of cases, it was better." Thus, both students and instructors urged the importance of social presence, their responsibility in cultivating it, and its benefits for a blended learning program.

\section{Contradictory Results among the Data Artifacts}

Overall, the data analysis process suggests social presence is complex and difficult to measure. Although the data analysis process yielded an $80.1 \%$ inter-rater reliability result, the coded data conflicted significantly with other qualitative data sources, including instructor interviews and observation notes. Whereas instructors and students in the program commented at length during their interviews about how the second cohort was so closely bonded and connected (also validated by the author's observation notes), the coded data suggested that the first cohort appeared to be more socially present (see Figure 2).

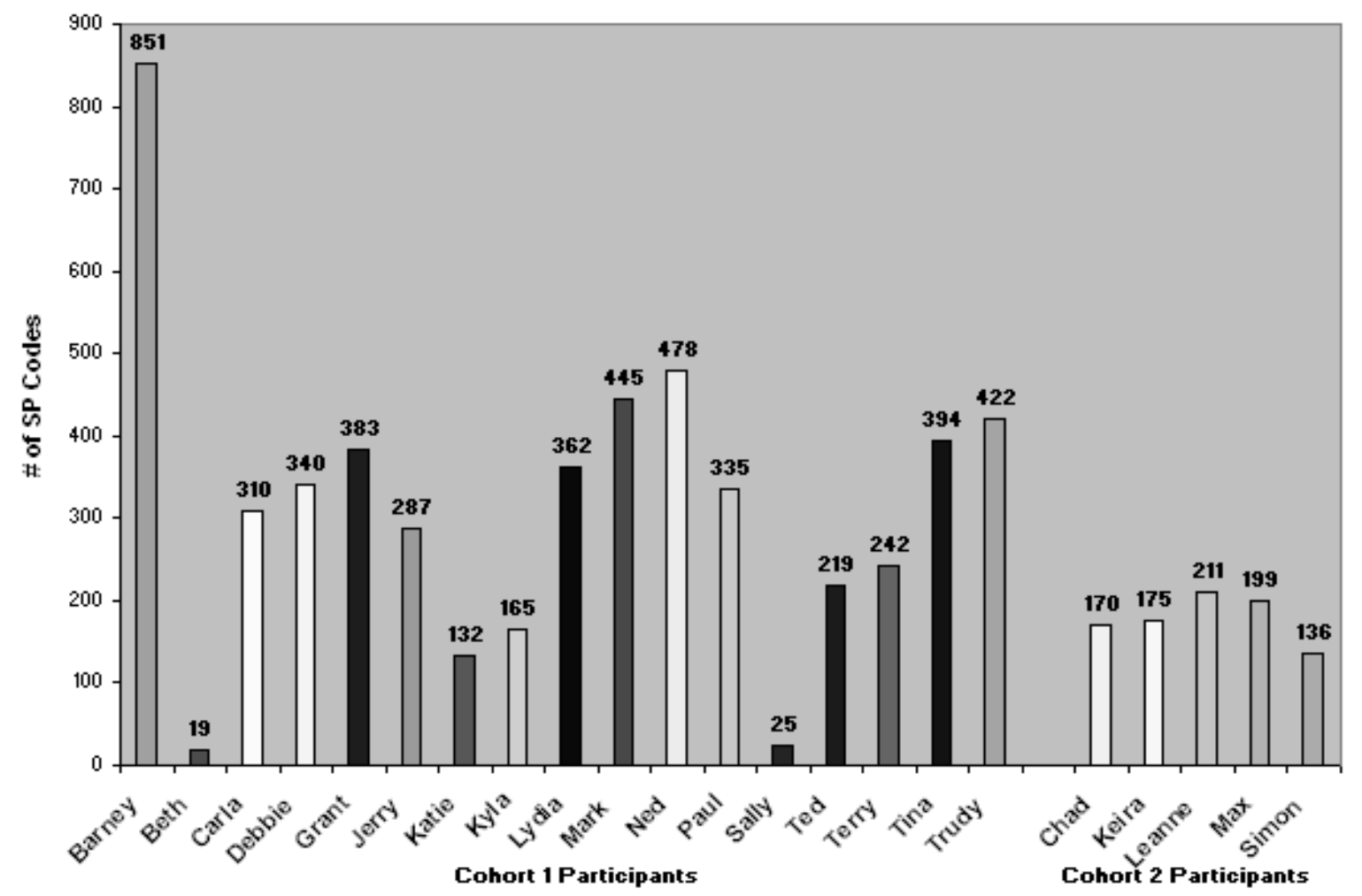

Figure 2: Social presence code comparison between the cohorts

The results showed that in Cohort 1 the total number of codes across all 17 participants averages to roughly 316 social presence codes per participant; likewise, the average Cohort 2 participant yielded 
only 178 codes. Even after removing a few outliers in Cohort 1, the average Cohort 1 participant yielded nearly double the amount of codes of the average Cohort 2 participant. Based on the coding data, Cohort 1 was more socially present than Cohort 2 . However, interestingly, the other forms of data suggest that this assumption is flawed. The results from several interview transcriptions and the author's observation notes from over a dozen face-to-face courses told a much different story that centered on Cohort 2 as being more socially present.

For example, one set of observation notes in the first summer session of Cohort 2 stated, "Great community in this class" (observation, July 6, 2004). The following excerpt from the author's observation notes for the last day of class for Cohort 2 noted the close emotional connection in Cohort 2: "Very emotional. Keira thank[ed] everyone for their support. Cried.” (observation, July 12, 2005). In contrast, observation notes from Cohort 1 detected very few instances of emotion and focused more on academic interaction among the participants.

The instructor interviews suggest Cohort 2 to be much more socially present than Cohort 1 . One instructor, Dr. Mike Stanley, commented, "The second group was very, very tight. I think mostly because they were such a small group; there were basically just five of them” (personal communication, May 3, 2006). Another instructor, Dr. Sarah Finch, also found the smaller size of Cohort 2 impacted their level of social presence. She stated: "I think everybody in the second cohort participating in the classes was socially present” (personal communication, May 1, 2006). In regard to Cohort 1, Dr. Finch explained that she was "kind of surprised at times" when "even in the last day, they didn't know each other's names." Overall, she added: "I don't think that there was as deep or as much connectedness in the first cohort as there was in the second cohort." Thus, each of the other data artifacts from the author's observation notes from over a dozen courses to the instructor and student interview transcriptions clearly illustrated that Cohort 2 was far more socially present.

What could be the explanation for the data disparity? Interestingly, Chad, a student in Cohort 2, mentioned that there were a lot of connections and instances of social presence in Cohort 2 that occurred outside of the learning environment (and outside of the data set), which might provide an explanation for the lower levels of social presence. Chad explained: "If I had a problem, I could call Simon or Max or email them and ask him questions about what they thought” (Chad, personal communication, January 16, 2007). Chad found that Cohort 2 participants would email "each other back and forth outside of the [online] discussion.” Thus, social presence existed in Cohort 2 beyond the data artifacts, which may present a reason why there are fewer codes in the learning environment for Cohort 2.

While Chad offers one potential explanation, after carefully examining the data, two key differences emerged between the cohorts that turned out to have significant impact on social presence: (a) the prior knowledge and experience of the participants and (b) the instructors' involvement and instructional strategies.

\section{Knowledge and Experience as a Component of Social Presence}

The first cohort consisted of seventeen students with a wide range of experienced educational leaders. With a few exceptions, Cohort 1 participants' positions involved district-level positions where participants' responsibilities and decisions directly affected dozens of teachers and staff members as well as hundreds to thousands of students. Also, in terms of titles, Cohort 1 embodied a vast range of positions, including an Associate Principal, Database Administrator/Programmer, Leadership Forum Director, High School Staff Development Specialist, Dean of Students, Director of Technology, and Director of Instructional Media and Technology; whereas, Cohort 2 consisted largely of middle school teachers.

Thus, Cohort 2 collectively possessed far less leadership experience and knowledge. Most Cohort 2 members worked in a classroom, not in an administrative leadership setting. As a result, there was a wealth of leadership experience in Cohort 1 that was not present in Cohort 2. Simon, a student in Cohort 2, explained why the difference in leadership experience was important and how it affected social presence. He mentioned the benefits of a closely-knit small cohort, and he suggested his only regret about being part of a smaller cohort was there was not "extra perspectives" from which everyone could learn (Simon, personal communication, August 9, 2006). Without a vast collective knowledge base the 
participants could, as Simon suggests, lose the motivation to "keep up with the discussion," whereby the online discussion becomes "lacking" (Simon, personal communication, August 9, 2006).

Simon addresses the lack of "extra perspectives," which connects directly to the sociocultural framework for this study. Specifically, Vygotsky's (1978; 1986) concept of the More Knowledgeable Other (MKO) within the Zone of Proximal Development (ZPD) suggests there is a relationship between the classes' collective knowledge and learning potential. Educational researcher Gordon Wells (2000) helps us understand how the ZPD plays a significant role in knowledge acquisition. He explains that "although no member has expertise beyond his or her peers, the group as a whole, by working at the problem together, is able to construct a solution that none could have achieved alone” (p. 324). This perspective helps to understand how the lack of MKOs limits Cohort 2's ability to gain more knowledge. Moreover, Simon illustrates that a group's collective prior experiences and knowledge level have a significant impact on social presence as well as student learning. The lack of prior knowledge and experiences for Cohort 2 also relates to another key difference between the two cohorts: Instructor Involvement.

\section{Instructor Involvement as a Component of Social Presence}

The instructors of the program, Drs. Mike Stanley and Sarah Finch, used the same core curriculum for both cohorts. Yet, as instructors often do, they saw some room for improvement after Cohort 1 and made minor changes to their instructional approach for Cohort 2.

For example, Sarah Finch observed some Cohort 1 participants responded with a flippant word or two to fulfill the two-post requirement in online discussions. As a result, Dr. Finch added a new requirement for Cohort 2. The Cohort 2 students still needed to meet a particular number of discussion posts, but also had to qualify their answers using categories Dr. Finch developed, such as Substantive Insight, Clarification Question, Affirmation, and Collegial Challenges. Students were required to use these categories in the subject line of their discussion post and to adhere to the definition of the category they selected. Through the categorization, Dr. Finch sought to change students' levels of thoughtfulness from a quick "yeah that's really cool" to high levels of critical thinking where students were "metacognitively aware of what they were posting" (S. Finch, personal communication, May 1, 2006). As a result of this change, the average words per discussion post moved from an average of 179 words in Cohort 1 to an average of 203 words in Cohort 2. As Dr. Finch hoped, the discussion posts for Cohort 2 offered a much more thoughtful approach than in the previous year. However, as an unintended result, the data suggests this change adversely affected the level of social presence. One student interviewed in Cohort 2, Simon, referred to the online categories in the posts in as "more academic" and not connected to his needs (personal communication, August 9, 2006).

Another change by the instructors involved adjusting to the lack of leadership experience in Cohort 2. Since many of the Cohort 2 students were not in a position to influence the leadership of their educational organization, the instructor adjusted coursework accordingly. Table 2 shows a contrast between the questions asked of students in Cohort 1 and Cohort 2 in an online school policy course. The highlighted areas represent how this instructor situated the learning with Cohort 1 versus taking a more academic approach with Cohort 2.

This table shows a clear contrast between questions that situate learning within a cohort's work environment (Cohort 1 Questions) and questions that target the academic course materials (Cohort 2 Questions). Simon, a Cohort 2 student, sheds light on the difference to students in the second cohort. During an interview he continually referred to the online discussions as the "academic" part of the program. Such a distinction had not been mentioned by any members of Cohort 1 . Simon considered the online part to be academic because he perceived it as being based only on the course readings, not based on his or his organization's needs (personal communication, August 9, 2006). Thus, because of the difference in prior experience, the instructors adjusted the content in ways that ultimately affected the level of social presence in the course. 
Table 2: Comparison of Online Discussion Prompts

\begin{tabular}{|c|c|}
\hline Cohort 1 Questions & Cohort 2 Questions \\
\hline $\begin{array}{l}\text { Does your district have a policy in place } \\
\text { to deal with issues such as those } \\
\text { described in this article? If so, how is it } \\
\text { working (also, please post as an } \\
\text { attachment so that others can see some } \\
\text { models!)? Is it a good policy for dealing } \\
\text { with these kind of issues or does it have } \\
\text { some shortcomings? If your } \\
\text { organization doesn't have such a policy, } \\
\text { what are the disadvantages of that } \\
\text { approach? }\end{array}$ & $\begin{array}{l}\text { What policy issues remain unresolved } \\
\text { after the first two national educational } \\
\text { technology plans? What old priorities } \\
\text { should the third national plan continue to } \\
\text { address? What new priorities also should } \\
\text { be included? Please give a short } \\
\text { explanation / justification for your } \\
\text { answer(s) [this is important in the policy } \\
\text { context where different agendas compete } \\
\text { for attention and/or funding]. }\end{array}$ \\
\hline $\begin{array}{l}\text { Does your organization ask itself the } \\
\text { questions Fowler says it should as it } \\
\text { implements educational technology } \\
\text { policy? What stage(s) is your } \\
\text { organization in for some of these various } \\
\text { educational technology policies? What } \\
\text { from Fowler will be particularly useful to } \\
\text { you as you think about your } \\
\text { organization's educational technology } \\
\text { policy implementation? }\end{array}$ & $\begin{array}{l}\text { What policy issues remain unresolved } \\
\text { after the first two national educational } \\
\text { technology plans? What old priorities } \\
\text { should the third national plan continue to } \\
\text { address? What new priorities also should } \\
\text { be included? Please give a short } \\
\text { explanation / justification for your } \\
\text { answer(s) [this is important in the policy } \\
\text { context where different agendas compete } \\
\text { for attention and/or funding]. }\end{array}$ \\
\hline $\begin{array}{l}\text { Which of Dye's categories does it use to } \\
\text { evaluate the efficiency and effectiveness } \\
\text { of educational technology policy } \\
\text { implementation (or does it not evaluate } \\
\text { at all)? What are the advantages and/or } \\
\text { disadvantages of your organization's } \\
\text { approach? }\end{array}$ & $\begin{array}{l}\text { When you look at the national } \\
\text { educational technology policy initiatives } \\
\text { that have taken place to date (e.g., E- } \\
\text { Rate, PT3 program, community } \\
\text { technology centers, etc.), how would you } \\
\text { describe them? Are they examples of } \\
\text { mandates, inducements, capacity } \\
\text { building, system changing, and/or } \\
\text { persuasion? Would the impact of these } \\
\text { national policy initiatives have been } \\
\text { more successful if they had taken a } \\
\text { different form [be sure to describe how } \\
\text { you are conceiving of impact, using the } \\
\text { terminology from Dye.pdf]? }\end{array}$ \\
\hline $\begin{array}{l}\text { On a scale of } 1 \text { (terrible) to } 10 \\
\text { (excellent), what overall rating would } \\
\text { you give your state right now? What is } \\
\text { your state doing particularly well? What } \\
\text { is your state doing particularly poorly? } \\
\text { What should your state be doing } \\
\text { differently and how might it get there } \\
\text { (remember: it's easy to articulate } \\
\text { problems but not so easy to articulate } \\
\text { workable solutions)? }\end{array}$ & $\begin{array}{l}\text { What are your reactions to your readings } \\
\text { about state-level technology leadership } \\
\text { issues? What were your thoughts and/or } \\
\text { questions as you went through these } \\
\text { readings? }\end{array}$ \\
\hline
\end{tabular}


In sum: after analyzing the data, two key missing components of social presence emerged as the differences between the cohorts: (a) the importance of the knowledge and experience of the participants; and (b) the importance of the instructors' involvement and the instructional strategies selected between the two cohorts. These features are as central to social presence as the categories in the original Social Presence Coding Scheme: affective, cohesive, and interactive. Therefore, these two missing elements along with the Social Presence Coding Scheme are combined to form the Social Presence Model (Whiteside, 2007).

\section{Introducing the Social Presence Model}

This study examines social presence as a powerful, overarching concept (Garrett Dikkers \& Whiteside, 2008, 2013; Garrett, Whiteside, Hughes \& McLeod, 2005; Whiteside, 2007; in press; Whiteside \& Garrett Dikkers, 2008; 2009; 2010; 2012; in press; Whiteside, Garrett Dikkers \& Lewis, 2014a, 2014b, 2015). It sees social presence as a master conductor that synchronizes the instructor, students, norms, academic content, learning management system (LMS), media, tools, instructional strategies, and outcomes within a learning experience. Although the original Social Presence Coding Scheme is a great indicator of affect, cohesion and interaction, this multi-year study suggests that it takes far more to define social presence. After examining the data, two important components that affect social presence emerged: a) participants' knowledge and experience and b) instructor involvement.

Thus, this study expands the Social Presence Coding Scheme into the Social Presence Model. It includes the original categories in the coding scheme and adds two key, additional components. Based on the data, social presence involves five integrated elements-Affective Association, Community Cohesion, Instructor Involvement, Interaction Intensity, and Knowledge and Experience-that together affect participants' motivation to take an active role in their own and their peers' learning. To help understand this definition the Social Presence Model in Figure 3 illustrates the five elements that define social presence (Whiteside, 2007).

\section{Affective Association}

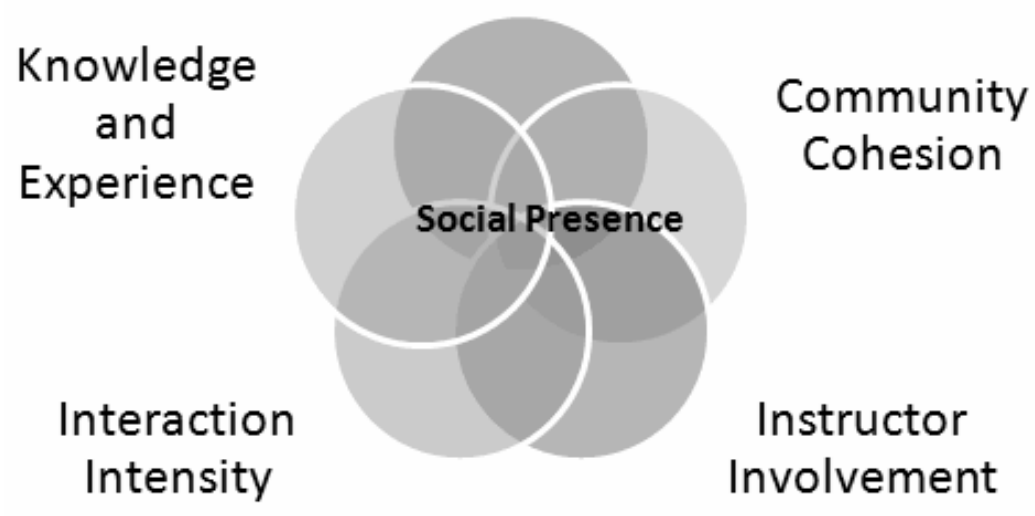

Figure 3: The Social Presence Model

The following sub-sections define each element of the Social Presence Model: (a) Affective Association, (b) Community Cohesion, (c) Instructor Involvement, (d), Interaction Intensity and (e) Knowledge and Experience.

Affective Association The Affective Association category addresses the emotional connections which occur within the program. This area, which targets instances of emotion, humor and self disclosure related to personal emotion, is represented though the Affective category of the Social Presence Coding Scheme (Rourke, Anderson, Garrison and Archer, 1999; Polhemus, Shih \& Swan, 2001; Swan, 2002). It also addresses paralanguage, such as all caps, boldface font style, and emoticons or emojis. Instructor Mike 
Stanley finds that if students do not "trust those people and respect those people," then they are not going to feel the emotional connection (M. Stanley, personal communication, May 3, 2006). Dr. Stanley continues that, if students do not feel an emotional bond, then they are not going to "put it out there," and, then, they "can't learn from it." As students invest emotionally in their course community, they can become more invested in the academic course content (Conrad \& Donaldson, 2004; Conrad \& Donaldson, 2011). In addition to Affective Association, Community Cohesion marks another key component of social presence.

Community Cohesion Community Cohesion relates to the course community. This area includes sharing additional resources and information with the group as well as seeing the group as a cohesive whole. It also involves being an approachable group member, which includes codes for greetings, salutations, and vocatives (referring to others by name) as well as sharing information and resources with others. Chad, a student in Cohort 2, finds that "cohort means cohesiveness" (personal correspondence, January 17, 2007). For Chad, the cohort relationship was a big part of social presence. Chad distinguished between being "just part of a group" versus the bonding he experienced in the cohort through activities. Chad explained:"I think as you work together, you're working towards a goal.”

Instructor Mike Stanley agreed with Chad's explanation. He suggested, “I think that if you're feeling disconnected from your class peers, you don't have as much intrinsic incentive to engage in discussion [and] to connect others to resources that you know about” (M. Stanley, personal communication, May 3, 2006). This statement from Dr. Stanley helps illustrate the interconnected nature of social presence elements, and his role leads to our next element: Instructor Involvement.

Instructor Involvement Another important element for social presence which emerged from the literature and the data is the true importance of the instructor's involvement. Each one of the students interviewed mentioned instructors' initial community building "activities" were essential to them in establishing relationships and making social connections. Likewise, it is also important for instructors to push their students to engage in critical analyses and higher-order thinking in the online environment. For example, Figure 4 offers three sequential messages between Leanne and her instructor, Dr. Stanley, which illustrate the relationship between instructor involvement and social presence.

Topic: Schmoker Discussion

Date: May 11, 2005 10:14 PM

Subject: Re:Chapter 1 (Teaming)

Author: Leanne

In my limited experience, teaming can be a fabulous professional experience, but much is dependent upon the quality and style of leadership and the climate that is established. If cooperation and respect, along with high expectations for all, are modeled, team members will be more likely to interact with these values in mind. If a tone of competition and rivalry is set, then teams will be negatively impacted and less likely to be successful.

Topic: Schmoker Discussion

Date: May 12, 2005 1:35 PM

Subject: WHERE IS OUR GOOD LEADERSHIP WHEN WE MOST DESPERATELY NEED IT?

Author: Stanley, Mike

Well said, Leanne, but it's too bad that this even has to be said in the first place... WHERE IS OUR GOOD LEADERSHIP WHEN WE MOST DESPERATELY NEED IT?

Topic: Schmoker Discussion 
Introducing the Social Presence Model to Explore Online and Blended Learning Experiences

Date: May 12, 2005 9:13 PM
Subject: Re:WHERE IS OUR GOOD LEADERSHIP WHEN WE MOST DESPERATELY
NEED IT?
Author: Leanne
Thanks for your response, Mike.
I think the problem is that there really isn't much good leadership out
there. More often, it's management that is happening, even when it is
called leadership. I have been musing on the difference between the two
(another article idea!) and have come to some conclusions.
Leaders take you somewhere, they have vision and the understand the big
picture, and are able to communicate where they are taking you and why.
They inspire trust and elicit respect, although you may not agree with
them. They also trust the members of their organization,
and because they trust them, they have high expectations for them.
Participating in this sort of environment feels good. Management is
different in that frequently there is not alot [sic] of leading going on.
Managers either try to keep you where you're at or they attempt to herd
you where they want you to go. They do not inspire trust or respect. They
seldom have vision, but are generally just trying to stay under the radar
and "do their job." Being managed does not feel good and can result in
feeling of resentment. What best illustrates this for me is how it used to
feel in the classroom when everything was working: I wanted to take the
kids somewhere, and they were coming willingly- it's an incredible high.
Conversely, the days, or weeks, or...) I felt that I was doing purely
crowd control felt like crap- there was little reward in it, for anyone.

Now as far as how we've gotten to this point...but, that's another discussion. It felt so good to write this!

Figure 4: Discussion Illustrating Instructor Involvement and Social Presence

In this lengthy example, the student, Leanne, began with a discussion of how team success depends on leadership. Her account was initially written using passive voice, and she seemed to strive to avoid any agency. For example, she talks about "the quality and style of leadership" and need for the concepts of "cooperation and respect" to be "modeled." When the instructor sensed her frustration and provided some feedback, the tone of Leanne's response completely changed. Her words suggested she felt more comfortable stating her points, and, at the end of her message, exclaimed, "It felt so good to write this!” In terms of social presence, Leanne's first message was coded only for Social Sharing and for Comments or Opinions. After the instructor's feedback, her second message, in contrast, showed the following codes: Acknowledgement, Compliment or Agreement, Emotion, Opinions or Comments, Paralanguage, Social Sharing, and Vocative. This example illustrates the importance of the instructor for engaging and growing social presence within a learning experience. As the instructor helped the student express their thoughts and ideas, we also see a key example of Vygotsky's concept of inner speech in an online learning environment.

Interaction Intensity Interaction Intensity, by definition, consists of the level of interaction between participants. Interaction Intensity is included in the original Social Presence Coding Scheme (Rourke, Anderson, Garrison and Archer, 1999; Polhemus, Shih \& Swan, 2001; Swan, 2002). It includes acknowledgements, which can be a direct quote from another classmate or a paraphrased version of another classmate's previous statement, such as "I enjoyed the way you integrated Finch's framework into your district" or "Your thoughts and analysis about copyright really got me thinking about how it is handled in our district" (S. Finch, personal communication, May 1, 2006). Interaction Intensity involves agreement, disagreement, compliments, and questions. For example, Figure 5 provides a discussion 
response from Cohort 1's School Technology Policy Issues course and offers an example of Interaction Intensity.

Subject:Re:ClO

Author: Debbie Date: December 8, 2003 9:07 AM

\begin{abstract}
I agree with the others. Like Paul \& Trudy, our Technology Coordinator is a non-cabinet position. Our Technology Coordinator did recently retire. He was formerly a classroom teacher, so like $\mathrm{T}$ rudy, it was a step in the right direction. He had the classroom perspective, and had enough working knowledge on the tech front to know what had to be done and to surround himself with the right folks. However, we always seemed to be in an infrastructure focus, which is what was needed at the time.

Well, now that we have the infrastructure \& hardware in place, we need to begin the integration focus, to which our previous coordinator would have lent much knowledge \& experience to know what was needed in the classrooms. We are thrilled with his successor (who had been his assistant), but she is without the classroom experience as she is just tech-savy. Luckily, she is aware of this fact. It is my hope that she will surround herself with the correct people and build a working knowledge of what must happen now.

For the utopian position, I also concur that a CIO would be most beneficial. But, it comes down to resourcesboth [sic] time, money and persomel.
\end{abstract}

Figure 5: Example of Interaction Intensity

In this message, Debbie shows her agreement with Paul and Trudy, and she refers to her classmates by name (vocative), which showed her level of investment in the discussion.

Knowledge and Experience Finally, another one of the important new themes that emerged from the literature and the data is that prior knowledge and experiences play an essential role in building social presence. Cohort 1 participants' occupations included various district-level leadership positions that directly affected dozens of teachers and staff members and thousands of students, and they, as a community of learners, offered each other continual advice based on their tremendous expertise. Cohort 2, in contrast, consisted largely of teachers without the leadership roles and experience of the first cohort.

The methodology for this manuscript, and, specifically, Vygotsky's Zone of Proximal Development (ZPD), provides an explanation why the combined present knowledge of Cohort 2 is much less than that Cohort 1. Wells (2000) explains that the group's potential equates to the sum of its parts. Without the depth of the knowledge base in Cohort 1, the Cohort 2 participants can, as Simon suggests, lose the motivation to "keep up with the discussion" (personal communication, August 9, 2006). Thus, a group's collective experience and knowledge level has an impact on social presence. Without the vast collective knowledge to share and the willingness to share it, the number of potential connections reduces, which also reduces the level of social presence.

Overall, the Social Presence Model with its five integrated elements can serve as a heuristic for instructors and students as well as an important tool for current and future research (Garrett Dikkers \& Whiteside, 2008, 2013; Garrett, Whiteside, Hughes \& McLeod, 2005; Whiteside, 2007; in press; Whiteside \& Garrett Dikkers, 2008; 2009; 2010; 2012; in press; Whiteside, Garrett Dikkers \& Lewis, 2014a, 2014b, 2015). Social presence affects learning only to the extent that instructors and students are willing to integrate the five elements of social presence. Likewise if the class is not affectively invested in one medium (face-to-face or online) in a blended program, the level of social presence can drop for the entire course. In this study, the lack of connectedness in the online discussions diminished the overall social presence for Cohort 2. Thus, maximizing each of the five elements of social presence in each medium of a program can contribute to a more powerful overall learning experience.

The next section highlights some data-driven discoveries from this study with the hope that researchers will continue to explore social presence in different contexts. 


\section{Discussion}

This section highlights several key findings from this four-year study on social presence in a blended learning program. The data from this study (a) introduce the Social Presence Model, (b) recommend revisiting the Social Presence Coding Scheme, (c) highlight the importance of multiple data types and informal learning, and (d) determine that blended learning programs demand exceptional facilitation.

\section{Introduced the Social Presence Model}

A major contribution of this research involves the addition of two more essential elements to further the understanding of social presence: (a) prior knowledge and experience and (b) instructor involvement and instructional strategies and activities. These additional elements merge with the existing elements of the existing coding scheme to form the Social Presence Model of five integrated elements (Affective Association; Community Cohesion; Instructor Involvement; Interaction Intensity; and Knowledge and experience) that together determine a participant's motivation to take an active role in their own and their peers' learning. This model is comparable to the COI; the distinct difference is that social presence serves as the overarching principle that drives learners, instructors, academic content, norms, behaviors, instructional strategies, activities, and outcomes.

\section{Recommended Revisiting the Social Presence Coding Scheme}

Although the Social Presence Coding Scheme offers an essential first step to determining social presence, this study as well as other studies, suggests that it needs careful revision to more accurately determine a concept as complex as social presence (Lowenthal \& Dunlap, 2014). For example, the coding scheme needs to be weighted. For example, currently an instance of deep self disclosure counts the same as someone using all caps or an exclamation in a post, which results in an inaccurate portrayal of social presence. Likewise, the coding scheme must better determine what constitutes "high" and "low" levels of social presence across courses and programs. Finally, a universal shared codebook would help with coding consistency and overall questions. For example, should a student providing an additional resource count as Community Cohesion or Interaction Intensity? Also, should Social Sharing count as Affective Association, Community Cohesion, or Interaction Intensity, or should it be coded for all of them? This author recommends the Social Presence Coding Scheme receive careful examination and consistent protocols for research.

\section{Highlighted the Importance of Multiple Data Types and Informal Learning}

Because of the discrepancies in the data, having multiple types of data proved imperative for this study. Going forward, social presence researchers may wish to consider a number of varied data sources, including but not limited to interview transcriptions, email/Facebook/Twitter/chat/phone/text correspondences, blog responses, video conferences, course assignments, observation transcriptions (from online sessions), and online discussions. These varied data sources help triangulate the results.

Additionally, the author recommends that future studies consider both the formal and informal learning environments because social presence extends beyond the confines of the formal learning environment. Researchers may wish to request IRB approval to study students' day-to-day texts as well as Facebook, Twitter, Tumblr, Word Press, email, chat, and phone correspondences. This study determined that a large amount of unrecorded social presence happened outside of the scope of the study, which limited the study's ability to accurately access the amount of social presence.

\section{Determined that Blended Learning Programs Demand Exceptional Facilitation}

Finally, this study shows that instructors bear a multitude of responsibilities in blended learning programs. Not only do they have the pressures of developing a clear organizational structure and employing content expertise, but instructors must also consider the role of social presence in that process. As illustrated in Table 2, even seemingly small changes can alter the social dynamics of a learning community.

Furthermore, the instructor and students' roles and responsibilities change in each medium of a blended learning program. The instructor(s) must be effective facilitators in each medium while carefully 
Introducing the Social Presence Model to Explore Online and Blended Learning Experiences

scaffolding their learners through the content. In particular, instructors must facilitate social connections as the students make the transition from a face-to-face classroom to an online learning environment and vice versa. Blended learning programs challenge instructors to be flexible, to wear a number of different hats (active participant, expert, facilitator, and cheerleader), and to think critically about the affordances of the different media in order to continually engage students in meaningful learning and to maintain social presence.

Blended learning programs challenge researchers as well. One discovered weakness of this study is that the author relied on observation notes for over a dozen one-credit face-to-face courses across both cohorts. In the future, this author suggests researchers consider audio or video transcriptions to more accurately capture face-to-face experiences and to better balance data from both the online and the faceto-face components of the blended learning experience. When researching blended learning programs, it is vital to consider the interplay between the online and face-to-face components as well as to fully examine all components of the program.

\title{
Conclusion
}

This study explored social presence within the first two cohorts of a 13-month graduate-level certificate program designed to help school administrators integrate technology into their districts. Vygotsky's Social Development Theory served as the theoretical framework to explore this programmatic data. This study employed the pre-established Social Presence Coding Scheme by Rourke, Anderson, Garrison and Archer (1999), Polhemus, Shih \& Swan (2001), and Swan (2002). The coded data showed a disparity in social presence between the two cohorts, which conflicted with other data artifacts, including interview transcriptions and observation notes. Further analysis indicated that the Social Presence Coding Scheme did not completely define social presence-there were two important missing elements. Accordingly, the study unveiled the Social Presence Model, which includes a combination of the three components from the original Social Presence Coding Scheme and the two missing elements. Thus, the Social Presence Model consists of the following five integrated elements: Affective Association, Community Cohesion, Instructor Involvement, Interaction Intensity and Knowledge and Experience.

In closing, social presence is important in blended learning programs because the shifting literacies in multimodal learning environments create unique challenges and opportunities for teaching and learning with profound consequences for learners and instructors (Selber, 2004). Instructors are still exploring the affordances of a mix of face-to-face and online environments and are continually learning more about how to maximize student learning in a multimodal program (Bender, 2012). Blended learning programs are challenging because instructors and learners are toggling among the different media, which requires a lot of adaptability and increases the need for social presence. Therefore, this research provides an exploration of one landscape of learning that may lead to future explorations and advancements within educational discourse. The author recommends more programmatic studies that explore social presence, especially in blended learning programs. Additionally, we need studies that target the role of assessment, engagement, and student learning outcomes (SLOs) in concert with social presence.

Correspondence concerning this article should be addressed to

\author{
Aimee L. Whiteside \\ Department of English and Writing \\ University of Tampa \\ 416 Plant Hall, Box R \\ 401 W. Kennedy Blvd. \\ Tampa, FL 33606 \\ Contact: awhiteside@ut.edu
}


Introducing the Social Presence Model to Explore Online and Blended Learning Experiences

\section{References}

Arbaugh, J. B. (2005). Learner-centered theory and practice in distance education: Cases from higher education. Academy of Management Learning \& Education, 4(2), 256-258.

Bender, T. (2012). Discussion-based online teaching to enhance student learning: Theory, practice and assessment. $2^{\text {nd }}$ ed., Sterling, VA: Stylus Publishing.

Boston, W., Diaz, S. R., Gibson, A. M., Ice, P., Richardson, J., \& Swan, K. (2010). An exploration of the relationship between indicators of the community of inquiry framework and retention in online programs. Journal of Asynchronous Learning Networks, 13(3), 67-83.

Cleveland-Innes, M., \& Campbell, P. (2012). Emotional presence, learning, and the online learning environment. The International Review of Research in Open and Distance Learning, 13(4), 269292.

Cleveland-Innes, M., Ally, M., Wark, N., \& Fung, T. (2013). Emotional presence and mobile learning: Learner-driven responses in a wireless world. European Journal of Open, Distance, and eLearning. Retrieved from http://www.eurodl.org/?p=special\&sp=articles\&inum=5\&article=623

Conrad, R., \& Donaldson, A. (2004). Engaging the online learner: Activities and resources for creative instruction. San Francisco: Jossey-Bass.

Conrad, R., \& Donaldson, A. (2011). Continuing to engage the online learner: More activities and resources for creative instruction. San Francisco: Jossey-Bass.

Daspit, J. J., \& D'Souza, D. E. (2012). Using the community of inquiry framework to introduce wiki environments in blended-learning pedagogies: Evidence from a business capstone course. Academy of Management Learning \& Education, 11(4), 666-683.

Dunlap, J.C. \& Lowenthal, P. R. (2009). Tweeting the night away: Using twitter to enhance social presence. Journal of Information Systems Education, 20(2): 129-135.

Dunlap, J.C., \& Lowenthal, P.R. (2014). The power of presence: Our quest for the right mix of social presence in online courses. In A. A. Piña \& A. P. Mizell (Eds.), Real life distance education: Case studies in practice (pp. 41-66). Greenwich, CT: Information Age Publishing.

Garrett Dikkers, A., \& Whiteside, A.L. (2008, August). Using the Social Presence Model to maximize online learning. Paper presented at the $24^{\text {th }}$ Annual Conference on Distance Teaching and Learning. Madison, WI.

Garrett Dikkers, A. \& Whiteside, A.L. (2013, October). Creating Social Presence in asynchronous online learning. Paper presented at the Global Learning Technology Conference, Wilmington, NC.

Garrett Dikkers, A., Whiteside, A.L., \& Lewis, S, (2012, September/October). Get present: Build community and connectedness online. Learning \& Leading with Technology, 40(2), 22-25.

Garrison, D. R. Community of Inquiry Model. http://www.communityofinquiry.com, Accessed December 21, 2012.

Garrison, D. R. \& Akyol, Z. (2008). The development of a community of inquiry over time in an online course: Understanding the progression and integration of social cognitive and teaching presence,” Journal of Asynchronous Learning 12,3-4.

Garrison, D. R., Anderson, T., \& Archer, W. (2000). Critical inquiry in a text-based environment: Computer conferencing in higher education. The Internet and Higher Education, 2(2-3), 87-105.

Garrison, D. R., Anderson, T., \& Archer, W. (2010). The first decade of the community of inquiry framework: A retrospective. The Internet and Higher Education, 13(1-2), 5-9.

Garrison, D. R., \& Arbaugh, J. B. (2007). Researching the community of inquiry framework: Review, issues, and future directions. The Internet and Higher Education, 10(3), 157-172. 
Introducing the Social Presence Model to Explore Online and Blended Learning Experiences

Garrison, D. R. (2009). Communities of inquiry in online learning. In P. L. Rogers, Berg, G. A., Boettcher, J. V., Howard, C., Justice, L., \& Schenk, K. D. (Eds.), Encyclopedia of distance learning (2nd ed.) (pp. 352-355). Hershey, PA: IGI Global.

Garrison, D. R. (2011). E-Learning in the 21st century: A framework for research and practice (2nd ed.). London: Routledge/Taylor and Francis.

Garrison, D. R., \& Cleveland-Innes, M. (2005). Facilitating cognitive presence in online learning: Interaction is not enough. American Journal of Distance Education, 19(3), 133-148.

Gunawardena, C., Lowe, C. A. \& Anderson, T. (1997). Analysis of a global online debate and the development of an interaction analysis model for examining social construction of knowledge in computer conference. Journal of Educational Computing Research, 17(4), 397-431.

Gunawardena, C. N., \& Zittle, F. J. (1997). Social presence as a predictor of satisfaction with a computermediated conferencing environment. American Journal of Distance Education, 11, 8-26.

Gunawardena, C. N. (1995). Social presence theory and implications for interaction and collaborative learning in computer conferences. International Journal of Educational Telecommunications, 1(2/3), 147-166.

Hughes, J. E., McLeod, S., Garrett Dikkers, A., Brahier, B., \& Whiteside, A. L. (2005). School technology leadership: Theory to practice. Academic Exchange Quarterly (Special Issue on Leadership), 9(2), 51-55.Lomicka, L. \& Lord, G. (2007). Social presence in virtual communities of foreign language (FL) teachers. System, 35, 208-228.

Lowenthal, P. R. \& Dunlap, J. C. (2010). From pixel on a screen to real person in your students' lives: Establishing social presence using digital storytelling. Internet and Higher Education, 13(1), 7072.

Lowenthal, P. R., \& Dunlap, J. C. (2014). Problems measuring social presence in a Community of Inquiry. E-Learning and Digital Media, 11(1), 19-30.

Lowenthal, P. R. (2009). The evolution and influence of social presence theory on online learning. In T. T. Kidd (Ed.), Online education and adult learning: New frontiers for teaching practices (pp. 124-139). Hershey, PA: IGI Global.

Lowenthal, P. R. (2010). The Evolution and Influence of Social Presence Theory on Online Learning. In T. T. Kidd (Ed.), Online education and adult learning: New frontiers for teaching practices. Hershey, PA: IGI Global.

McLeod, S. Center for the Advanced Study of Technology Leadership in Education. University Council of Educational Administration. http://schooltechleadership.org/, accessed December 22, 2012.

Merriam, S. (1989). Case study research in education: Qualitative approach. San Francisco: Jossey-Bass Publishers.

Nagel, L., \& Kotze, T. (2010). Supersizing e-learning: What a CoI survey reveals about teaching presence in a large online class. The Internet and Higher Education, 13(1-2), 45-51.

Na Ubon, A., \& Kimble, C. (2003). Supporting the creation of social presence in asynchronous textbased online learning communities. Paper presented at the Proceedings of the $5^{\text {th }}$ International Conference on Information Communication Technologies in Education.

Nippard, E. \& Murphy, E. (2007). Social presence in the web-based synchronous secondary classroom. Canadian Journal of Learning and Technology, 33(1), 90-109.

Oztok, M. \& Brett, C. (2011). Social presence and online learning: A review of the research. The Journal of Distance Education, 25(3), 1-10.

Palloff, R. M., \& Pratt, K. (2007). Building online learning communities: Effective strategies for the virtual classroom. San Francisco: Jossey-Bass.

Phillips, L. \& Jorgensen, M. (2002). Discourse analysis: As theory and method. London: Sage. 
Picciano, A. G. (2002). Beyond student perceptions: Issues of interaction, presence, and performance in an online course. Journal of Asynchronous Learning Networks, 6(1), 21-40.

Polhemus, L., Shih, L. F., \& Swan, K. Virtual interactivity: The representation of social presence in an online discussion. Paper presented at the annual meeting of the American Educational Research Association, Seattle, WA (2001).

Rettie, R. Connectedness, awareness, and social presence. 6th International Presence Workshop. Aalborg, 1, 2003. http://eprints.kingston.ac.uk/2106/1/Rettie.pdf, accessed November 10, 2006.

Richardson, J. C. \& Swan, K. (2003). Examining social presence in online courses in relation to students' perceived learning and satisfaction. Journal of Asynchronous Learning Networks, 7(1), 68-88.

Rourke, L., Anderson, T. Garrison, D. R., \& Archer, W. (1999). Assessing social presence in asynchronous, text-based computer conferencing. Journal of Distance Education, 14(2): 50-71.

Salomon, G. \& Perkins, D. N. (1998). Individual and social aspects of learning. In: Pearson, P.D., and Iran-Nejad, A. (Eds.), Review of Research in Education 23, 1-24.

Selber, S. Multiliteracies for a digital age. Carbondale, Illinois: Southern Illinois University Press, 2004.

Shea, P., \& Bidjerano, T. (2009a). Cognitive presence and online learner engagement: A cluster analysis of the community of inquiry framework. Journal of Computing in Higher Education, 21, 199217.

Shea, P., \& Bidjerano, T. (2009b). Community of inquiry as a theoretical framework to foster "epistemic engagement" and "cognitive presence" in online education. Computers \& Education, 52, 543553.

Shea, P., \& Bidjerano, T. (2010). Learning presence: Towards a theory of self-efficacy, self-regulation, and the development of a communities of inquiry in online and blended learning environments. Computers \& Education, 55(4), 1721-1731.

Shea, P., Li, C. S., \& Pickett, A. M. (2006). A study of teaching presence and student sense of learning community in fully online and web-enhanced college courses. The Internet and Higher Education, 9, 175-190.

Short, J., William, E., \& Christie, B. (1976). The social psychology of telecommunications. Toronto, ON: Wiley.

Stake, R. (1998). Case study research. In Denzin, N. K. \& Lincoln, Y. S. (Eds.), Strategies of Qualitative Inquiry, Thousand Oaks, CA: Sage Publications, 86-109.

Stake, R. Case studies. (2000). In Denzin, N. K. \& Lincoln, Y. S. (Eds.), Handbook of Qualitative Research, 2nd ed., Thousand Oaks, CA: Sage Publications, 435-454.

Swan, K. \& Shih, L.-F. (2005). On the nature and development of social presence in online course discussions. Journal of Asynchronous Learning Networks, 9(3), 115-136.

Swan, K. (2002). Immediacy, social presence, and asynchronous discussion. In J. Bourne \& J. C. Moore (Eds) Elements of Quality Online Education 3. Needham, MA: Sloan Center for Online Education.

Tammelin, M. (1998). From telepresence to social presence: The role of presence in a network-based learning environment. In Tella, S. (Ed.), Aspects of Media Education: Strategic Imperatives in the Information Age. University of Helsinki. Media Education Publications. http://www.europeanmediaculture.org/fileadmin/bibliothek/english/tammelin_telepresence/tammelin_telepresence.htm l, accessed November 2, 2006.

Tu, C.-H., \& McIsaac, M. (2002). The relationship of social presence and interaction in online classes. The American Journal of Distance Education, 16(3), 131-150.

Tu, C.-H. (2002). The measurement of social presence in an online learning environment. International Journal on E-Learning 1(2): 34-45. 
Twigg, C. (2001). Innovations in online learning: Moving beyond no significant difference. The Pew Symposia in Learning and Technology.

Vygotsky, L. S. (1978). Mind in society: The development of higher psychological processes. Cambridge: Harvard University Press.

Vygotsky, L. S. (1986). Thought and language. Cambridge: MIT Press.

Wells, G. (2000). Dialogic inquiry in education: Building on the legacy of vygotsky. In: Lee, C. D., and Smagorinsky, P. (Eds.), Vygotskian Perspectives on Literacy Research: Constructing Meaning through Collaborative Inquiry. Cambridge, MA: Cambridge University Press.

Wenger, E. (1998). Communities of practice: Learning, meaning, and identity. Cambridge: Cambridge University Press.

Whiteside, A. L., \& Garrett Dikkers, A. (2008, September). Social presence in online learning. Paper presented at the New Media Research Conference. University of Minnesota. Minneapolis, MN.

Whiteside, A. L., \& Garrett Dikkers, A. (2009, April). Strategies for maximizing learning outcomes and student engagement in online and blended learning environments. Workshop presented at the Academy of Distinguished Teachers Teaching and Learning Conference, Minneapolis, MN.

Whiteside, A. L., \& Garrett Dikkers, A. (2010, October). Strategies to maximize online interactions using the Social Presence Model. Paper presented at the Online Learning Consortium Conference, Orlando, FL.

Whiteside, A. L., \& Garrett Dikkers, A. (2012). Using the Social Presence Model to maximize interactions in online environments. In K. St. Amant \& S. Kelsey (Eds.), Computer-mediated communication across cultures: International interactions in online environments (pp. 395-413). Hershey, PA: IGI Global.

Whiteside, A. L., \& Garrett Dikkers, A. (in press). Leveraging the Social Presence Model: A decade of research on emotion in online and blended learning. In S. Tettegah, \& R. Ferdig, (Eds.) Emotions, Technology, and Learning. Elsevier.

Whiteside, A. L., Garrett Dikkers, A., \& Lewis, S. (2014, May/June). The power of social presence for learning. EDUCAUSE Review Online. Retrieved from http://www.educause.edu/ero/article/power-social-presence-learning.

Whiteside, A. L., Garrett Dikkers, A., \& Lewis, S. (2014, October). Looking to the future of social presence: Theory, research, and practice. Paper presented at the Online Learning Consortium Annual Conference, Orlando, FL.

Whiteside, A. L., Garrett Dikkers, A., \& Lewis, S. (2015, April). Connectedness, Learning, and the Social Presence Model: A Decade of Research on Online and Blended Learning in Higher and K-12 Education. Paper presented at the American Educational Research Association Annual Conference, Chicago, IL.

Whiteside, A. L., Hughes, J. E., \& McLeod, S. (2005). Interconnecting cognition, contact, and comprehension: The influence of social presence in a hybrid-model certificate program. Proceedings of the New Media Research Conference. University of Minnesota, Minneapolis, MN.

Wise, A., Chang, J., Duffy, T., \& del Valle, R. (2004). The effects of teacher social presence on student satisfaction, engagement, and learning. Journal of Educational Computing Research, 31(3), 247271.

Yin, R. (2003). Case study research: Design and methods. 3rd ed., London: Sage. 